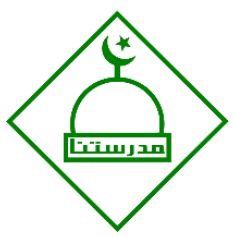

\title{
Pengaruh sarana prasarana terhadap efektivitas proses pembelajaran di SDN 1 Maparah Ciamis
}

\author{
Try Riduwan Santoso ${ }^{1}$, Dena Putri ${ }^{2}$ \\ Institut Agama Islam Latifah Mubarokiyah, Tasikmalaya, Indonesia \\ tryriduwan165@gmail.com,Putridena050@gmail.com
}

\begin{abstract}
ABSTRAK:
Tujuan penulisan artikel ini adalah untuk mengetahui bagaimana sarana prasarana terhadap efektivitas proses pembelajaran di SDN 1 Maparah Kecamatan Panjalu Kabupaten Ciamis, mengetahui pengaruh sarana prasarana terhadap efektivitas proses pembelajaran di SDN 1 Maparah Kecamatan Panjalu Kabupaten Ciamis. Sarana prasarana mencakup semua peralatan dan perlengkapan yang secara langsung dipergunakan dan menunjang dalam proses pembelajaran. Sarana pembelajaran diperlukan untuk menunjang proses pembelajaran agar peserta didik lebih mudah menerima penjelasan dari guru. Semakin lengkap dan memadai sarana pembelajaran yang dimiliki sekolah akan memudahkan guru dalam melaksanakan tugasnya sebagai tenaga pendidikan. Metode yang digunakan dalam penelitian ini adalah metode deskriptif melalui pendekatan kuantitatif. Teknik pengumpulan data yang dilakukan penelitian ini dengan observasi, wawancara, dan angket. Koefisien korelasi antara variabel $\mathrm{X}$ dengan variabel $\mathrm{Y}$ adalah sebesar 0,35 maka berada pada klasifikasi cukup karena terletak pada interval 0,41-0,60, hasil uji signifikasi 0,05 dan (dk= 34-2=32) diperoleh $t_{\text {tabel }} 2,0315$. Dengan demikian $t_{\text {hitung }} 4,13 \geq t_{\text {tabel }} 2,0315$. Sehingga Hipotesis Alternatif $(\mathrm{Ha})$ diterima, sedangkan Hipotesis $\mathrm{Nol}(\mathrm{H} 0)$ ditolak. Artinya sarana prasarana memiliki pengaruh terhadap efektivitas proses pembelajaran di SDN 1 Maparah Kecamatan panjalu Kabupaten Ciamis sebesar $35 \%$. Pengaruh tersebut antara lain dari ruang belajar, buku dan sumber belajar, media pembelajaran, ruang perpustakaan, tempat laboratorium, tempat berolahraga.
\end{abstract}

Kata kunci : Sarana dan prasarana, pembelajaran dan guru

\section{The influence of infrastructure on the effectiveness of the learning process at SDN 1 Maparah Ciamis}

\begin{abstract}
This study aims to find out how the infrastructure of the effectiveness of the learning process at SDN 1 Maparah, Panjalu District, Ciamis Regency, knowing the effect of infrastructure on the effectiveness of the learning process at SDN 1 Maparah, Panjalu District, Ciamis Regency. Infrastructure facilities include all equipment and equipment that are directly used and support in the learning process. Learning facilities are needed to support the learning process so that students more easily receive explanations from the teacher. The more complete and adequate learning facilities owned by the school will make it easier for teachers to carry out their duties as education staff. The method used in this study is descriptive method through a quantitative approach. Data collection techniques carried out by using observation, depth interview, and questionnaires. The results of the analysis is that the correlation coefficient between variable $\mathrm{X}$ and variable $\mathrm{Y}$ is 0.35 . So it is in sufficient classification because it is located at intervals of $0.41-0.60$, the
\end{abstract}

\footnotetext{
${ }^{1}$ Dosen IAILM Suryalaya

${ }^{2}$ Alumni PGSD/MI IAILM Suryalaya
} 
result of significance test is 0.05 and $(\mathrm{dk}=34-2=32)$ is obtained t table 2,0315 . Thus $t_{\text {count }} 4.13 \geq t_{\text {table }}$ 2.0315. So the Alternative Hypothesis ( $\mathrm{Ha}$ ) is accepted, while the Zero Hypothesis (H0) is rejected. This means that the infrastructure has an influence on the effectiveness of the learning process at SD 1 Maparah, Panjalu District, Ciamis Regency on $35 \%$. Those are learning room, reading book and resource, learning media, Library, laboratory, and sport facility

Keyword : Facility, Learning, Teacher

\section{PENDAHULUAN}

Pada dasarnya proses belajar mengajar merupakan inti dari proses pendidikan secara keseluruhan, diantaranya guru merupakan salah satu faktor yang penting dalam menentukan berhasilnya proses belajar mengajar di dalam kelas. Oleh karena itu, guru dituntut untuk menigkatkan peran dan kompetensinya, guru yang kompeten akan lebih mampu menciptakan lingkungan belajar yang efektif dan akan lebih mampu mengelola kelasnya sehingga hasil belajar siswa berada pada tingkat yang optimal. Sebagaimana peranan guru salah satunya yaitu guru sebagai pengelola kelas, mediator dan fasilitator serta penggunaan fasilitas atau sarana prasarana dalam keberlangsungan kegiatan pembelajaran (Komarudin, Ukim. (2015), Mulyasa (2006).

Pembelajaran efektif adalah pembelajaran yang menfokuskan pada pengembangan unsur kompetensi peserta didik. Pembelajaran efektif dapat ditinjau dari sisi hasilnya yakni berhasil mengembangkan potensi knowledge, skill, behavior, dan values setiap peserta didik sehingga menjadi insan yang luasnya pengetahuannya, cakap keterampilan, bijak sikapnya karena pemahaman nilainilai yang menjadi dasar hidupnya dan selaras berperilaku hidup dengan sesamanya (Komarudin, 2015:9).

Pembelajaran efektif adalah proses belajar mengajar yang bukan saja terfokus kepada hasil yang dicapai peserta didik namun, bagaimana proses pembelajaran yang efektif mampu memberikan pemahaman yang baik, kecerdasan, ketekunan, kesempatan dan mutu serta dapat memberikan perubahan perilaku dan mengaplikasikannya dalam kehidupan mereka (Rusyan, Tabrani, dkk, 2005:48).

Salah satu aspek yang seyogyanya mendapat perhatian utama oleh setiap administrator pendidikan adalah mengenai sarana dan prasarana pendidikan. Sarana pendidikan umumnya mencakup semua peralatan dan perlengkapan yang secara langsung dipergunakan dan menunjang dalam proses pendidikan, seperti : gedung, ruang belajar atau kelas, alat-alat/media pndidikan, meja, kursi dan sebagainya. Sedangkan yang dimaksud dengan prasarana adalah fasilitas yang tidak langsung menunjang jalannya proses pendidkan, seperti : halaman, kebun/taman sekolah, jalan menuju ke sekolah (Muhammad Ali, 2007). 
Manajemen sarana prasarana pendidikan merupakan suatu proses pengelola sarana prasarana supaya berfungsi dengan baik sehingga antara guru dan peserta didik keduanya dapat saling menjalankan tugasnya dengan baik pula dan tujuan pendidikan dapat tercapai secara optimal (Komara, Cucu dan Deuis Fitni, 2014:23).

Tujuan pengelolahan sarana prasarana pendidikan adalah memberikan pelayanan serta profesional dibidang sarana prasarana pendidikan dalam rangka terselenggaranya proses pendidikan secara efektif dan efisien Bambang (2015). Jika mengajar dipandang sebagai proses penyampaian materi, maka dibutuhkan sarana pembelajaran berupa alat dan bahan yang dapat menyalurkan pesan secara efektif dan efesien.

Tugas guru merupakan suatu proses mendidik, mengajar dan melatih peseta didik. Mendidik berati meneruskan dan mengembangkan nilai-nilai hidup (afektif). Mengajar berarti meneruskan dan mengembangkan ilmu pengetahuan dan teknologi (kognitif). Adapun melatih berarti mengembangkan keterampilan para siswa (psikomotor) Faoz, Rusman. (2015). Guru adalah sebagai sebuah profesi adalah tenaga kependidikan yang berkualitas sebagai guru, dosen, konselor, pamong belajar, widyaiswara, tutor, instruktur, fasilitator, dan sebutan lain yang sesuai dengan kekhususannya, serta berpartisipasi dalam menyelenggarakan pendidikan (Suryana, 2014: 9). Dan dalam proses belajar mengajar tugas utama guru dalam mengelola kelas adalah menciptakan suasana di dalam kelas agar terjalin interaksi belajar mengajar. Dan juga dapat terjadinya pembelajaran yang efektif dan efisien (Underwood, 2000:37). Pembelajaran efektif adalah proses belajar mengajar yang bukan saja terfokus kepada hasil yang dicapai peserta didik, namun bagimana proses pembelajaran yang efektif mampu memberikan pemahaman yang baik, kecerdasan, ketekunan, serta dapat memberikan perubahan perilaku dan mengaplikasikanya dalam kehidupan mereka.

Menurut Jasin dalam E.C.Wragg (1996:8) pengelolaan kelas adalah segala sesuatu yang dilakukan guru agar anak-anak berpartisipasi aktif dalam kegiatan belajar mengajar.

Sedangkan menurut Danim (2014:63) mengatakan bahwa pengelolaan kelas adalah sebagian bagian dari sekolah secara keseluruhan yang menjadi pusat/tempat terjadinya proses belajar mengajar.

Menurut Rusdiana (2014:65) mengatakan bahwa :

Pengelolaan kelas adalah suatu usaha yang dilakukan untuk mencapai tujuan pengajaran. Dengan kata lain, pengelolaan kelas merupakan kegiatan pengatur kelas untuk kepentingan pengajaran. Dalam konteks itulah, pengelolaan kelas penting untuk diketahui oleh pihak-pihak yang menerjunkan dirinya dalam dunia pendidikan. 
Pengelolaan kelas merupakan keterampilan yang harus dimiliki guru dalam memutuskan, memahami, mendiagniosa dan kemampuan bertindak menuju perbaikan suasana kelas. Selain memberi makna penting bagi tercipta dan terpeliharanya kondisi kelas yang optimal.

Menurut Purwoko dalam Underwood (1993:39) menciptakan suasana dalam kelas yaitu melibatkan setiap peserta didik dalam proses pembelajaran dan berikan kesempatan kepada peserta didik dalam mengemukakan pendapat.

Seorang guru harus mampu menciptakan suasana atau kondisi belajar dikelas. Ia juga harus mampu merangsang peserta didik untuk aktif dalam proses pembelajaran, terampil mengajar, mengendalikan suasana dalam kelas, pembelajaran menarik, dan pembelajaran kondusif. (Sukadi, 2006:20).

Sebaiknya di sekolah dasar sarana prasarana sesuai dengan standar kriteria minimum sarana yang meliputi: ruang kelas, ruang perpustakaan, laboratorium IPA, ruang pimpinan, ruang guru, tempat ibadah, ruang uks, jamban, gudang, ruang sirkulasi, tempat olahraga (Ismaya, 2015:16).

Menurut E. Mulyasa (2006:43) mengatakan bahwa:

Standar sarana dan prasarana adalah standar nasional pendidikan yang berkaitan dengan kriteria minimal tentang ruang belajar, tempat berolahraga, media pembelajaran, perpustakan, laboratoruim, serta buku dan sumber belajar, termasuk penggunaan teknologi informasi dan komunikasi.

Sarana prasarana merupakan fasilitas pendukung yang dapat menunjang proses kegiatan dalam pendidikan. Sarana prasarana yang dikelola dengan baik akan memudahkan guru dalam mengajar dan juga menambah kenyamanan peserta didik dalam belajar.

Standar sarana ditetapkan dengan PP. No.19 tahun 2005 tentang standar Sarana Prasarana menjelaskan bahwa Standar nasional pendidikan yang berkaitan dengan kriteria minimal tentang ruang belajar, tempat berolahraga, tempat beribadah, tempat berkreasi, serta sumber belajar lain, yang diperlukan untuk meunjang proses pembelajaran, termasuk penggunan teknologi informasi dan komunikasi.

Menurut Sanjaya (2014:28) mengatakan bahwa :

Sarana adalah segala sesuatu yang mendukung secara langsung terhadap kelancaran proses pembelajaran, misalnya dalam media pembelajaran, alat-alat pelajaran, perlengkapan sekolah, dan lain sebagainya. Sedangkan prasarana adalah sesuatu yang secara tidak langsung dapat mendukung keberhasilan proses pembelajar misalnya jalan menuju sekolah, penerangan sekolah, kamar kecil, dan lain sebagainya 
Sebagaimana dalam Standar Nasional Pendidikan Bab VII Pasal 42 yang berbunyi:

1) Setiap satuan pendidikan wajib memiliki sarana yang meliputi perabot, peralatan pendidikan, media pendidikan, buku dan sumber belajar lainnya, bahan habis pakai, serta perlengkapan lain yang diperlukan untuk menunjang proses pembelajaran yang teratur dan berkelanjutan.

2) Setiap satuan pendidikan wajib memiliki prasarana yang meliputi lahan, ruang kelas, ruang pimpinan, satuan pendidikan, ruang pendidik, ruang tata usaha, ruang perpustakaan, ruang laboratorium, ruang bengkel kerja, ruang unit produksi, ruang kantin, instalasi daya dan jasa, tempat berolahraga, tempat beribadah, tempat bermain, tempat berkreasi, dan ruang/tempat lain yang diperlukan untuk menunjang proses pembelajaran yang teratur dan berkelanjutan (Undang-undang Sisdiknas, 2013).

Sarana dan Prasarana di SDN 1 Maparah sudah memadai, hanya saja dalam penyimpanan, pengelolaan dan pemanfaatan kurang dimanfaatkan dalam proses pembelajaran. Hal ini dikarenakan guru kurang bisa menggunakan sarana dalam pembelajaran dan juga dalam penyimpanan sarana dijadikan satu ruangan yang menyebabkan guru sulit mencari sarana yang ada untuk menunjang keefektivan dalam proses pembelajaran.

Proses pembelajaran di SDN 1 Maparah kurang efektif dikarenakan guru kurang menguasai kelas, dan jumlah peserta didik yang banyak disetiap kelasnya. Guru kurang menggunakan media pembelajaran yang ada, seperti LCD Proyektor yang jarang digunakan dalam proses pembelajaran, serta kurangnya model pembelajaran yang digunakan oleh guru ketika proses pembelajaran berlangsung.

Dalam penggunaan metode pembelajaran guru hanya menggunakan metode ceramah, dan tanya jawab. Sehingga membuat pembelajaran tidak bervariatif yang menyebabkan peserta didik merasa jenuh dan membuat pembelajaran menjadi membosankan.

Masalah yang akan diteliti dalam penelitian ini adalah bagaimana pengaruh sarana prasarana terhadap efektivitas proses pembelajaran di SDN 1 Maparah. Adapun tujuannya yaitu untuk mengetahui pengaruh sarana prasarana terhadap efektivitas proses pembelajaran peserta didik di SDN 1 Maparah.

\section{METODE PENELITIAN}

Metode yang penulis gunakan dalam penelitian ini adalah metode deskriptif penelitian kuantitatif. Metode deskriptif yaitu metode yang berupaya memaparkan suatu permasalahan 
penelitian kuantitatif dan memberikan gambaran secara gamblang, aktual, sesuai fakta dan dilakukan dengan penelitian yang seksama melalui pengumpulan data, analisis data, dan juga penarikan kesimpulan-kesimpulan (Wawan, 2015: 17).

Sedangkan penelitian yang digunakan dalam peneliti ini adalah pendekatan kuantitatif dapat diartikan sebagai metode penelitian yang berlandaskan filsafat positivisme, digunakan untuk meneliti pada populasi atau sampel tertentu, teknik pengambilan sampel umumnya dilakukan secara random, pengumpulan data menggunakan instrument penelitian analisis yang bersifat kuantitatif atau statistik dengan tujuan untuk menguji hipotesis yang telah ditetapkan.

Data yang digunakan dalam penelitian ini adalah data primer dan data sekunder. Data primer adalah data yang diperoleh secara langsung dari subjek atau objek penelitian, sedangkan data sekunder adalah data yang sudah dikumpulkan oleh pihak lain. Adapun teknik pengumpulan data yang digunakan dalam penelitian ini adalah:

a. Observasi

Observasi diartikan sebagai pengamatan dan pencatatan dengan sistematik terhadap gejala yang tampak pada objek penelitian. Dengan observasi pengamatan dan pencatatan dilaksanakan secara sistematis terhadap objek yang diselidiki. Observasi yang dilakukan adalah dengan melakukan pengamatan yang berkaitan tentang bagaimana pengaruh sarana prasarana terhadap efektivitas proses pembelajaran. Untuk memudahkan peneliti untuk mengetahui hal tersebut, maka peneliti melihat secara langsung ke lokasi penelitian.

b. Wawancara

Wawancara merupakan suatu proses memperoleh penjelasan untuk mengumpulkan informasi dengan menggunakan tanya jawab atau dengan kata lain, wawancara merupakan kegiatan untuk memperoleh informasi secara mendalam tentang sebuah isu atau tema yang diangkat dalam penelitian. Wawancara yang digunakan adalah wawancara terstruktur yang berupa wawancara bebas dimana peneliti tidak menggunakan pedoman wawancara yang telah tersusun secara sistematis dan lengkap untuk pengumpul datanya. Pedoman wawancara yang yang digunakan garis-garis besar permasalahan yang akan ditanyakan.

c. Angket

Angket merupakan teknik pengumpul data yang di lakukan dengan cara memberi seperangkat pertanyaan atau pernyataan tertulis untuk dijawab oleh responden. Bentuk angket yang digunakan penulis adalah angket tertutup dan langsung yang mana terdiri dari beberapa 
pertanyaan yang sudah tersedia jawabannya, pertanyaan disesuaikan dengan judul penelitian tentang pengaruh sarana prasarana terhadap efektivitas proses pembelajaran.

Untuk menghitung analisis data, penulis menggunakan teknik anlisis statistik, yang digunakan untuk menganalisis data sampel dan hasilnya diberlakukan untuk populasi. Sehubungan dengan penulisan ini akan melibatkan keterkaitan antara dua variabel pokok, yaitu variabel bebas (X) dan variabel terikat $(\mathrm{Y})$, maka untuk mengetahui tingkat hubungan pengaruh kedua variabel tersebut akan digunakan penganalisaan data berdasarkan rumus menurut Wawan (2015:199), menggunakan analisis korelasi dengan Rank Sperman (rs). Adapun urutan langkah-langkah penelitian ini, sebagai berikut:

1. Data Analisis variabel $X$ dan $Y$ (skor $X$ yang di dapat dari hasil penyebaran angket mengenai sarana prasarana dan skor $\mathrm{Y}$ dari efektivitas belajar)

a. Skoring data

b. Menghitung rata-rata atau mean dengan rumus:

$$
\bar{x}=\frac{\sum X_{i}}{n}
$$

c. Menentukan simpangan rata-rata dengan rumus:

$$
S_{R}=\frac{\sum\left|x_{1}-\bar{x}\right|}{n}
$$

d. Membuat skala penafsiran

\begin{tabular}{ll}
\hline Skor min +3 SR & Sangat Baik \\
\hline Skor min +2 SR & Baik \\
\hline Skor min +1 SR & Cukup \\
\hline
\end{tabular}

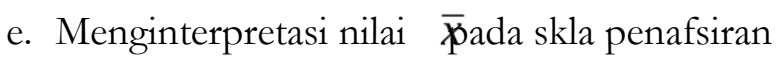

2. Menyusun analisis korelasi variabel $X$ terhadap variabel $Y$

a. Tabulasi data untuk menetukan variabel $\mathrm{X}$ dan $\mathrm{Y}$ dari yang terkecil sampai yang terbesar

b. Tabulasi data untuk menentukan beda rangking variabel $\mathrm{X}$ dan $\mathrm{Y}$

c. Menghitung korelasi antara variabel $\mathrm{X}$ dan variabel $\mathrm{Y}$ 


$$
r_{s}=1-\frac{6 \sum_{d i} 2}{N^{3}-N}
$$

d. Konfirmasi nilai rs pada skala guilford (wawan, 2015:202)

$$
\begin{aligned}
& 0,0-0,20=\text { very low (sangat rendah) } \\
& 0,21-0,40=\text { low (rendah) } \\
& 0,41-0,80=\text { high (tinggi) } \\
& 0,81-1,00=\text { very high (sangat tinggi) }
\end{aligned}
$$

e. Menentukan drajat determinasi dengan rumus

$$
D=r_{s}^{2} \times 100 \%
$$

f. Menguji hepotesis dengan rumus

$$
t_{\text {hitung }}=r s \sqrt{\frac{\mathrm{n}-2}{1-\mathrm{rs}^{2}}}
$$

\section{HASIL DAN PEMBAHASAN}

Lokasi penelitian yang diambil oleh peneliti adalah SDN 1 Maparah. SDN 1 Maparah merupakan sekolah pertama di Desa Maparah yang didirikan pada tahun 1947, di atas tanah seluas 1959m2 dengan bangunan sekolah berstatus milik pemerintah atau hak guna pakai. Sekolah ini bertempat di Dusun Pameungpeuk, Desa Maparah, Kecamatan Panjalu, Kabupaten Ciamis, Provinsi Jawa Barat dengan kode pos 46264. Berdirinya sekolah ini kiranya telah membantu anakanak yang berada di sekitarnya, khususnya yang berada di Dusun Pameungpeuk dan Dusun Cigintung dalam menjalankan kewajibannya sebagai manusia untuk mencari ilmu. Jarak yang cukup dekat antara sekolah dan tempat tinggal anak-anak, telah membuat mereka menjadi mudah dalam mendapatkan ilmu pengetahuan untuk bekalnya kelak di masa mendatang.

SDN 1 Maparah merupakan sekolah yang berstatus negeri dengan nomor statistik 101021404013 dan NPSN 20254240. Selama 5 tahun terakhir ini SDN 1 Maparah dikepalai oleh Mamat Rohimat S.Pd, M.M dengan NIP 196303071983051007 dan tercatat sebagai Pegawai Negeri Sipil (PNS) sejak 1983 dengan pangkat/golongan saat ini adalah IV/a. Dengan latar belakang kepala sekolah yang berpendidikan terakhir adalah S2 diharapkan akan membawa SDN 1 Maparah menjadi sekolah yang lebih baik lagi dalam segala bidang, baik dalam pengetahuan peserta didik maupun kinerja gurunya.

Berdasarkan hasil pengolahan data diperoleh Sarana prasarana, tergolong baik ( 31,5 yang berada pada interval 29,14 - 31,21 dengan klasifikasi baik). Sedangkan efektivitas proses pembelajaran, tergolong baik (34 berada pada interval 31,28 - 34,42 dengan klasifikasi baik), dan pengaruh sarana prasarana terhadap efektivitas proses pembelajaran di SDN 1 Maparah Desa 
Maparah berpengaruh positif dan signifikan dengan kategori cukup, terbukti $\mathrm{rs}=0,59$ berada pada interval $0,41-0,60$ serta $t_{\text {hitung }}(4,13) \geq t_{\text {tabel }}(2,0315)$ sarana prasarana menentukan efektivitas proses pembelajaran sebesar 35\% sedangkan sisanya 75\% dipengaruhi oleh faktor lain. Faktor yang memepengaruhi sebayak $35 \%$ adalah berasal dari, ruang kelas, media pembelajaran, perpustakaan, sarana olah raga dan laboratorium. Sedangkan sisanya 65\% antara lain efektifitas belajar anak dipengaruhi dari peran orang tua di rumah, gaya mengajar guru, dan factor teman belajar.

Teori E. Mulyasa (2006) sangat menekankan pentingnya sarana dan prasarana dalam proses pembelajaran di sekolah. Setelah penulis mengadakan penelitian tentang sarana prasarana terhadap efektivitas proses pembelajaran yang dilakukan di SDN 1 Maparah Desa Maparah Kecamatan Panjalu Kabupaten Ciamis, dapat disimpulkan sebagai berikut:

Sarana prasarana, setelah melakukan penyebaran angket kepada 34 orang peserta didik sebagai responden dengan nilai terendah 25, dan nilai tertinggi 37 didapat nilai rata-rata sebesar 31,5 berada pada interval 29,14 - 31,21 dengan klasifikasi sangat baik. Dengan demikian, dapat disimpulkan bahwa sarana prasarana di SDN 1 Maparah Desa Maparah Kecamatan Panjalu Kabupaten Ciamis adalah cukup. Hal tersebut dapat dilihat berdasarkan indikator-indikator sarana prasarana diantaranya ruang belajar, buku dan sumber belajar, media pembelajaran, ruang perpustakaan, tempat laboratorium dan tempat berolahraga.

Efektivitas proses pembelajaran, setelah melakukan penyebaran angket kepada 34 orang peserta didik sebagai responden dengan nilai terendah 25 dan nilai tertinggi 40 didapat nilai ratarata 34 berada pada interval 31,28 - 34,42 dengan klasifikasi baik. Dengan demikian, dapat disimpulkan bahwa efektivitas proses pembelajaran di SDN 1 Maparah Desa Maparah Kecamatan Panjalu Kabupaten Ciamis adalah cukup. Hal tersebut dapat dilihat berdasarkan indikatorindikator efektivitas proses pembelajaran diantaranya peserta didik aktif dalam pembelajaran, peserta didik aktif dalam tanya jawab, peserta didik menunjukan kegairahan belajar, peserta didik semangat dalam belajar.

Pengaruh sarana prasarana terhadap efektivitas proses pembelajaran di SDN 1 Maparah Desa Maparah Kecamatan Panjalu Kabupaten Ciamis, setelah dilakukan perhitungan didapat nilai rs sebesar 0,59, artinya bahwa korelasi sarana prasarana terhadap efektivitas proses pembelajaran memiliki pengaruh yang signifikan, setelah dikonfirmasi pada skala Guilford berada pada klasifikasi cukup (moderate) karena berada pada interval 0,41 - 0,60, sedangkan berdasarkan nilai determinasi pengaruh sarana prasarana terhadap efektivitas proses pembelajaran sebesar 35\% selanjutnya, hasil uji hipotesis menyatakan bahwa $t_{\text {hitung }} \geq t_{\text {tabel }}$ yaitu $4,13 \geq 2,0315$, sehingga Ha yang menyatakan sarana prasarana mempunyai pengaruh yang signifikan terhadap efektivitas proses 
pembelajaran di SDN 1 Maparah Desa Maparah Kecamatan Panjalu Kabupaten Ciamis diterima dan Ho yang menyatakan sarana prasrana tidak mempunyai pengaruh yang signifikan terhadap efektivitas proses pembelajaran di SDN 1 Maparah Desa Maparah Kecamatan Panjalu Kabupaten Ciamis ditolak. Ini membuktikan bahwa sarana prasarana mempunyai pengaruh yang signifikan terhadap efektivitas proses pembelajaran di SDN 1 Maparah Desa Maparah Kecamatan Panjalu Kabupaten Ciamis.

Hasil wawancara dengan guru kelas di SDN Maparah efektivitas belajar bahwa anak cenderung akan semangat belajar ketika mereka mempunyai buku, sehingga mereka akan focus untuk belajar, tanpa guru harus menjelaskan lebih panjang. Selanjutnya suasana ruang kelas dan media belajat juga sangat membantu guru dalam menjelaskan materi. Sehingga anak mudah memahami materi dengan baik. Walaupun pengaruh sarana dan prasana dalam standar cukup, tetapi sangat penting terhadap perkembangan hasil belajar siswa.

Sedangkan factor pengaruh efektivitas belajar anak lainnya dipengaruhi oleh banyak factor, seperti peran orang tua di rumah, gaya mengajar guru di kelas, teman belajar dan lainnya. Hal ini membutuhkan penelitian lanjutan kepada penelitian selanjutnya dengan mengambil tema pengaruh tersebut terhadap efektifitas di SDN 1 Maparah Ciamis.

\section{SIMPULAN}

Setelah penulis mengadakan penelitian tentang sarana prasarana terhadap efektivitas proses pembelajaran yang dilakukan di SDN 1 Maparah Desa Maparah Kecamatan Panjalu Kabupaten Ciamis, dapat disimpulkan sebagai berikut:

1. Sarana prasarana di SDN 1 Maparah Desa Maparah Kecamatan Panjalu Kabupaten Ciamis adalah cukup. Hal tersebut dapat dilihat berdasarkan indikator-indikator sarana prasarana diantaranya ruang belajar, buku dan sumber belajar, media pembelajaran, ruang perpustakaan, tempat laboratorium dan tempat berolahraga.

2. Efektivitas proses pembelajaran di SDN 1 Maparah Desa Maparah Kecamatan Panjalu Kabupaten Ciamis adalah cukup. Hal tersebut dapat dilihat berdasarkan indikator-indikator efektivitas proses pembelajaran diantaranya peserta didik aktif dalam pembelajaran, peserta didik aktif dalam tanya jawab, peserta didik menunjukan kegairahan belajar, peserta didik semangat dalam belajar.

3. Hasil uji hipotesis menyatakan bahwa $t_{\text {hitung }} \geq t_{\text {tabel }}$ yaitu $4,13 \geq 2,0315$, sehingga Ha yang menyatakan sarana prasarana mempunyai pengaruh yang signifikan terhadap efektivitas proses pembelajaran di SDN 1 Maparah Desa Maparah Kecamatan Panjalu Kabupaten 
Ciamis diterima dan Ho yang menyatakan sarana prasrana tidak mempunyai pengaruh yang signifikan terhadap efektivitas proses pembelajaran di SDN 1 Maparah Desa Maparah Kecamatan Panjalu Kabupaten Ciamis ditolak. Ini membuktikan bahwa sarana prasarana mempunyai pengaruh yang signifikan terhadap efektivitas proses pembelajaran di SDN 1 Maparah Desa Maparah Kecamatan Panjalu Kabupaten Ciamis.

\section{DAFTAR PUSTAKA}

Ali, Muhammad. (2007). Guru Dalam Proses Belajar Mengajar. Cetakan ketiga belas. Bandung: Sinar Baru Algensindo

Ariani, Niken dan Dany Haryanto. (2010). Pembelajaran Multimedia di Sekolah. Jakarta : Prestasi Pustaka

E. Mulyasa. (2006). Kurikulum Yang di Sempurnakan. Cetakan pertama. Bandung: Remaja Rosdakarya

Fadlilah. (2014). Implementasi Kurikulum 2013. Yogyakarta : Ar-ruzz Media

Faoz, Rusman. (2015). Media Pembelajaran. Latifah Press: Kompleks Pondok Pesantren Suryalaya.

Hamalik, Oemar. (2007). Dasar-dasar Pengembangan Kurikulum. Cetakan pertama. Bandung: Remaja Rosdakarya

Hani, Anisa. (2017). Sarana dan Prasarana Pembelajaran. 05 Mei. Diambil tanggal 25 Mei 2018 dari https://civitas.uns.ac.id

Helmawati. (2016). Pendidikan Keluarga. Cetakan kedua. Bandung: Remaja Rosdakarya Offset

Herawan, Endang dan Sukarti Nasihin. (2003). Pengelolaan Pendidikan. Yogyakarta : Rajawali

Ismaya, Bambang. (2015). Pengelolaan Pendidikan. Cetakan kesatu, Bandung: Refika Aditama

Komara, Cucu dan Deuis Fitni. (2014). Strategi Belajar Tuntas Di Sekolah Dasar. Bandung: Arcarya Media Utama

Komarudin, Ukim. (2015). Guru. Jakarta: Erlangga

Kurniawan, Heru. (2014). Pembelajaran Menulis Kreatif. Bandung: Remaja Rosdakarya

Rusdiana. (2015). Pengelolaan Pendidikan. Cetakan kesatu. Bandung: Pustaka Setia

Rusyan, Tabrani, dkk. (2005). Strategi Pengembangan Kari Guru Pendidikan Dasar. Cetakan Pertama. Bandung: Arcarya Media Utama

Sanjaya, wina. (2016). Strategi Pembelajaran Berorientasi Standar Proses Pendidikan. Bandung: Kencana

Sukadi. (2006). Guru Powerfull Guru Masa Depan. Cetakan kedua. Bandung: Kolbu 
Suryana, Nana. (2014). Profesi Keguruan.Latifah Press: Komplek Pondok Pesantren Suryalaya

Undang-undang Guru dan Dosen.(2011). Bandung: Fokus Media

Undang-undang Sisdiknas. (2013). Bandung: Fokus Media

Underwood, Marry. (2000). Pengelolaan Kelas yang Efektif. Jakarta: Arcan

Usman, Uzer. (1997). Menjadi Guru Profesional. Cetakan ke delapan belas. Bandung: Remaja Rosdakarya

Wawan. (2015). Statistika Pendidikan. Latifah Press: Komplek Pondok Pesantren Suryalaya , (2015). Desain Penelitian Kuantitatif. Latifah Press: Komplek Pondok Pesantren Suryalaya.

Wragg. (1996). Pengelolaan Kelas. Jakarta: Grasindo 